Phonological and grammatical production in children with developmental language disorder and children with hearing impairment.

\title{
Simon Sundström*
}

Department of Clinical and Experimental Medicine, Faculty of Medicine and Health Sciences, Linköping University, SE-581 83, Linköping, Sweden. E-mail simon.sundstrom@liu.se, telephone +4613286780 .

\section{Ulrika Löfkvist}

Department of Special Needs Education, Faculty of Educational Sciences, University of Oslo, Helga Engs hus, Sem Sælands vei 7, 0371 Oslo, Norway. E-mail ulrika.lofkvist@isp.uio.no, telephone +4794832255 .

and

Department of Clinical Science, Intervention and Technology, Karolinska Institute, SE-141 86, Stockholm, Sweden.

\section{Björn Lyxell}

Department of Behavioural Sciences and Learning and Swedish Institute for Disability Research, Linköping University, SE-581 83, Linköping, Sweden. E-mail bjorn.lyxell@liu.se, telephone +4613282106 .

\section{Christina Samuelsson}

Department of Clinical and Experimental Medicine, Faculty of Medicine and Health Sciences, Linköping University, SE-581 83, Linköping, Sweden. E-mail simon.sundstrom@liu.se, telephone +4613286795 .

*Corresponding author. Department of Clinical and Experimental Medicine, Linköping University, Faculty of Medicine and Health Sciences, The University Hospital Campus, SE58183 Linköping, Sweden E-mail address: simon.sundstrom@liu.se 


\begin{abstract}
Children with hearing impairment (HI) are at an increased risk of developing speech and language problems similar to those of children with developmental language disorder (DLD), including difficulties with phonology and grammar. This study investigated similarities and differences in phonological and grammatical production between children with bilateral sensorineural HI $(n=14)$ and children with DLD $(n=30)$ between 4-6 years of age and agematched controls with typical language development and normal hearing (TLD) ( $n=29)$, all with Swedish as their first language. Production of consonants, vowels, stress patterns and tonal word accents was assessed in a picture naming task, and in a word and nonword repetition task. Grammatical production was assessed for verb and noun morphology, and syntax. While performance for both children with HI and DLD were generally significantly below that of the controls with TLD, production of accents and syntax emerged as relative strengths. There were few differences between the between the children with HI and DLD, but noun-adjective agreement in predicative was more challenging for the children with HI. The results have implications for language assessment and planning of intervention.
\end{abstract}




\section{Introduction}

Problems with phonology, morphology and syntax are common in children with developmental language disorder (DLD) ${ }^{1}$ or hearing impairment (HI) (Cleary, 2009; Schwartz, 2009). The fact that these populations develop language in different conditionswith and without normal hearing — but display partly similar language difficulties, warrant investigations of how they differ from each other. It can also be assumed that a subgroup of children with HI, at least 7\% (Tomblin et al., 1997), would have a language disorder independent of their hearing loss, although recent studies suggest that language problems are prevalent in as much as $50 \%$ of children with mild-moderate HI (Delage and Tuller, 2007). Recent studies suggest that children with HI wearing cochlear implants (CI) may experience greater deficits in phonological compared to morpho-syntactical ability, due to the higher demands on phonetic detail required (Nittrouer et al., 2014; Nittrouer et al., 2016).

Nonword repetition (NWR), i.e. repetition of word-like forms without meaning, is a complex task, involving hearing, working memory, speech perception and production (Coady and Evans, 2008). NWR has been identified as an indicator of language difficulties in children with specific language impairment (Dollaghan and Campbell, 1998), children with HI using cochlear implants (Nittrouer et al., 2014), and has also been found difficult for children with mild-moderate HI using hearing aids (Halliday et al., 2017). Given the potential usefulness of NWR as a diagnostic tool, detailed studies of repetition performance, and how it relates to different aspects of language ability, are motivated. Swedish-speaking children with DLD or HI exhibit problems with repetition of both segmental and prosodic features of nonwords (Ibertsson et al., 2008). There is also some evidence to support association of NWR to

\footnotetext{
${ }^{1}$ Following the recent debate on terminology for children who have persisting language difficulties, the term developmental language disorder (Bishop et al., 2017) is used here, and is considered more or less equivalent to e.g. 'language impairment', 'specific language impairment' or 'primary language impairment'.
} 
expressive phonology and grammar in Swedish-speaking children with DLD (Sahlén et al., 1999), and HI (Sundström et al., 2018).

The Swedish phoneme system has nine vowels, each with one short and one long realization, and 18 consonants (Riad, 2014). Production and contrastive use of the consonants /p/, /t/, /k/, $/ \mathrm{m} /, / \mathrm{n} /, / \mathrm{v} /$, /j/ and, /h/, and the vowels /a/, /a:/, /ع:/, /u:/, /o:/, typically develops before the age of four, and all phonemes except /r/, /6/, and /g/ are established before six years of age (Nettelbladt, 2007). Swedish has variable lexical stress between words, and a system with two tonal word accents. The tonal word accents are realized as distinct pitch patterns aligned with the stressed syllable of the word, and all stressed words have either tonal word accent 1 or 2 . Monosyllables and words with final stress have tonal word accent 1, while tonal word accent 2 requires an unstressed syllable after the stress (Bruce, 2012). The trochee is the predominant foot, i.e. syllables are arranged in a strong-weak pattern, and this is also the pattern preferred by children in the early stages of development. Tonal word accent 2 is typically developed before tonal word accent 1 , and contrastive use of the tonal word accents is established around the age of four (Peters and Strömqvist, 1996).

In typical Swedish grammatical development genitive -s is one of the first suffixes to appear, and approximately $80 \%$ of typically developing children use s-suffixation of nouns at 28 months of age (Berglund and Eriksson, 2000). Plural form suffixes also develop early. Definite form suffixes surface somewhat later, but precede the use of indefinite articles. Verb inflections tend to come somewhat later than inflection of nouns, and infinitives are typically used first, followed by present tense, supine forms, and preterite past tense (Håkansson and Hansson, 2007). Compound tenses expressing future and present perfect are developed later, 
and about $50 \%$ of children produce these forms at 28 months of age (Berglund and Eriksson, 2000).

Both free and bound grammatical morphemes in Swedish usually comprise unstressed syllables, which may present a challenge to children with DLD or HI due to short duration and low perceptual saliency (Leonard et al., 1997; Svirsky et al., 2002). Acquisition and use of these morphemes might also be constrained by the fact that they frequently occur in prosodic positions before the stress, outside the predominant trochaic stress pattern (Gerken, 1994; Hansson et al., 2003). The tonal word accent system is also related to morphology in that the assignment of tonal word accent 1 or 2 is predictable based on morphological factors (Bruce, 1977). For example, the stem lek-in combination with the present tense suffix -er forms the tonal word accent 1 word léker 'play/plays', but together with the infinitive suffix -a the result is the tonal word accent 2 word lèka '[to] play'.

\section{Study aims}

The aim of the present study was to explore similarities and differences between children with DLD, children with HI, and children with TLD, on phonological, including prosodic, and grammatical production. Children with DLD or HI are at an increased risk of both phonological and grammatical impairment. Children with DLD are expected to perform on a level below that of age-matched peers with TLD and normal hearing, as this is inherent in the condition. Children with HI can also be expected to achieve results that are, on average, below that of the TLD children, although the difference may be greater for phonological compared to grammatical production (Nittrouer et al., 2014; Nittrouer et al., 2016). 


\section{Method}

\section{Participants}

Three groups of children aged 4-6 years were included in the present study: children with DLD, children with HI, and children with TLD. Following ethical approval from the Regional Ethical Review Board in Linköping, Sweden (Dnr 2013/92-31), caregivers of all participants received written information about the study through speech-language or audiology clinics, or through preschools. They were also given the opportunity to further inquire about the study before deciding to let their children participate. The children were given simplified oral information prior to testing. To be eligible for inclusion, all children should be aged between 4 and 6 years, and use spoken Swedish, with a Central Swedish dialect, as their primary language. Further, the children could not have any known neurodevelopmental or psychiatric disorders. As part of a brief parental interview, information was collected about parental education, the children's use of hearing aids and cochlear implants, history of hearing deficits and educational setting. Nonverbal intelligence was assessed with the block design subtest of the Wechsler Preschool and Primary Scale of Intelligence, Third Edition (WPPSI-III) (Wechsler, 2005).

The group of children with DLD comprised 30 children, whereof 10 were boys and 20 girls. They ranged in age from 49 to 74 months $(M=59.3, S D=7.3)$. The specific inclusion criteria for the DLD group were that the children should have a confirmed diagnosis of developmental language disorder/language impairment, previously assessed by a clinical speech and language therapist (SLT). Their language deficits should be mainly phonological and/or grammatical, excluding pronounced lexical, semantic and pragmatic deficits. The 
children also had to be normally hearing from birth, without any history of hearing deficits, e.g. because of repeated otitis media with effusion, as reported by their caregivers.

The group of children with HI consisted of 14 children, 11 girls and three boys, aged between 48 and 80 months $(M=60.3, S D=9.8)$. Criteria for inclusion specific to this group of children were bilateral congenital sensorineural hearing impairment, and full time use of hearing aids or cochlear implants. Their degree of hearing impairment ranged from mild to profound (Clark, 1981). Nine children used conventional hearing aids on both ears, two children used both a cochlear implant and a hearing aid, and three children used bilateral cochlear implants. The median age at implantation of the first CI was 15 months (range 9.649.2), and the median age at first HA fitting was 29 months (range 3.0-55.9). Cause of hearing impairment was unknown for 12 of the children, inner ear malformation for one child, and suspected but not confirmed congenital cytomegalovirus (CMV) infection for one child. All children were raised in hearing, Swedish-speaking families, and attended preschool integrated in a mainstream educational setting. None of the children used sign language.

In the group of children with TLD, 29 children (18 girls and 11 boys) participated. They were between 49 and 80 months old $(M=61.3, S D=8.2)$, and came from the same geographical areas as the children with DLD or HI. The children with TLD could not have a diagnosed disorder of language or cognition, and should have normal hearing, without any history of hearing deficits, as reported by their caregivers.

\section{Procedures}


All children were tested by a SLT, in a quiet room, either at a hospital clinic, at home, or at the preschool. Total time of testing was about 90-120 minutes, including suitable breaks. If needed, the testing could be performed on separate days. All tests were administered in a randomised order.

\section{a Phonological production}

The children's ability to repeat segmental and prosodic lexical features were assessed in a picture naming task and in a word repetition (WR) and nonword repetition (NWR) task. The measures obtained were percentages of correctly produced consonants, vowels, stress patterns, and tonal word accents.

The short version of the Phoneme Test (Hellqvist, 1995) was used to assess phonological production when naming known words. The test includes 72 pictures corresponding to childappropriate words that give an overview of the child's phoneme inventory. Most Swedish phonemes and the most common consonant clusters are represented in different word positions. The targets as intended are 32 monosyllabic words, 32 disyllabic words, seven three-syllable words, and one five-syllable word. There is a variation in stress patterns, but penultimate stress is the most frequent in the word with more than one syllable. All monosyllables have tonal word accent 1 , and out of the multisyllabic words, 13 have tonal word accent 1 , and 27 have tonal word accent 2 . All child productions were accepted, even when they differed lexically from the words originally intended (e.g. saying handfat 'sink' instead of kran 'tap'). Words that the children did not attempt to produce were excluded from the analyses. All responses were audiorecorded and transcribed phonetically. 
Phonological production during repetition was examined using a WR and NWR task (Sundström et al., 2014). Twenty-five one- to five-syllable words and nonwords, matched pairwise for stress and tonal word accent were included. As far as possible, words have been chosen that are familiar to children, but no procedure was undertaken to ensure that the children did in fact know the words included. The task is designed to include all possible stress patterns, and for stress patterns that allow for either tonal word accent 1 or 2 (i.e. items with more than one syllable and non-final stress), there is one word/nonword with tonal word accent 1 and one with tonal word accent 2 . Stimuli were pre-recorded and presented at approximately $70 \mathrm{~dB}$ SPL. The children repeated either the words or the nonwords first, and were instructed to repeat them as well as they could. All responses were audiorecorded and transcribed phonetically. Non-responses were not included for further analysis.

\section{b Grammatical production}

Gramba (Hansson and Nettelbladt, 2004) was used for the assessment of grammatical production. In this test, Swedish verb morphology, nominal morphology, and syntax are targeted using sentence continuation and completion. For the purpose of the present study, 14 different subcomponents were analysed, which are described in table 1. 
Table 1. Description of the Gramba grammatical production test.

\begin{tabular}{|c|c|c|c|c|}
\hline & Max score & Targeted structures & Example & Translation \\
\hline \multicolumn{5}{|l|}{ Verb morphology } \\
\hline Present tense & 3 & Verb stem + suffix (-er) & köp-er & buys \\
\hline Past tense preterite & 3 & Verb stem + suffix (-te) & köp-te & bought \\
\hline Future tense & 3 & Auxiliary verb + infinite verb & ska köpa & will buy \\
\hline Past tense perfect & 3 & Auxiliary verb + supine verb & har köpt & has bought \\
\hline Copula & 3 & Copula verb & är & is \\
\hline \multicolumn{5}{|l|}{ Nominal morphology } \\
\hline Plural & 3 & Noun stem + suffix (-ar/-er/-or) & katt-er & cats \\
\hline Indefinite article & 3 & Article $(e n / e t t)+$ noun & en katt & a cat \\
\hline Definite form & 3 & Noun stem + suffix (-en/-et) & katt-en & the cat \\
\hline Noun phrase agreement & 4 & Article + adjective + noun & den stora katten & the big cat \\
\hline Genitive case & 3 & Noun stem + definite form suffix + genitive suffix $(-s)$ & katt-en-s & the cat's \\
\hline $\begin{array}{l}\text { Adjective predicative } \\
\text { agreement }\end{array}$ & 3 & Subject + copula + adjective & katten är gul & the cat is yellow \\
\hline \multicolumn{5}{|l|}{ Syntax } \\
\hline Negation placement & 3 & Auxiliary verb + negation + infinite verb & kan inte hoppa & cannot jump \\
\hline Relative clause & 3 & Relative pronoun + verb & som äter & who eats \\
\hline Topicalization & 4 & Topicalized word + verb + subject & sen sover de & then they sleep \\
\hline Total max score & 44 & & & \\
\hline
\end{tabular}

\section{Data analysis}

Based on transcriptions, percentages of correctly produced consonants (PCC), vowels (PVC), stress patterns, and tonal word accents were calculated for the Phoneme Test and the WR and NWR task. The formula used was (the number of correct productions/(the number of correct + incorrect productions)). Allophonic variants of phonemes were accepted (e.g. [ $\mathrm{\jmath}]$ instead of [r]), as were minor non-phonemic articulatory deviations (e.g. [s] instead of [s]).

Nonparametric Kruskal-Wallis tests were used to compare the groups (DLD, HI, TLD) on each of the phonological and grammatical measures, as well as on age, nonverbal intelligence, and maternal education. Significant main effects were followed up using pairwise comparisons with adjusted $p$-values, with the overall $a$-level set to 0.05 . For the pairwise comparisons, $r$ was used as an estimate of effect size; values above $0.10,0.30$, and 0.50 correspond to small, medium, and large effects, respectively (Cohen, 1992). 
Ten percent of the recordings from the phonological production tasks were transcribed by an experienced SLT to enable assessment of inter-rater reliability. Point-by-point agreement between the transcribers was calculated using the formula (number of agreements) / (number of agreements + disagreements) $\times 100$. Total agreement was $90.3 \%$ for segments (consonants and vowels combined), $97.4 \%$ for tonal word accents, and $97.1 \%$ for stress.

\section{Results}

No difference between the three groups were found for age or nonverbal intelligence, while there was an overall group difference with respect to maternal education $(H(2=6.12, p=$ 0.047). Mothers of the children with TLD had significantly more years of education, $M=$ 16.0, $S D=2.3$, compared to mothers of the children with HI, $M=14.0, S D=2.1(p=0.044, r$ $=0.29$ ). There were no differences between the children with TLD and DLD, or between children with DLD and HI.

\section{Phonological production}

Phonological production was assessed in three conditions: a naming task where the child used familiar words, as well as WR and NWR. The overall results on the phonological production tasks are displayed in figure 1. 


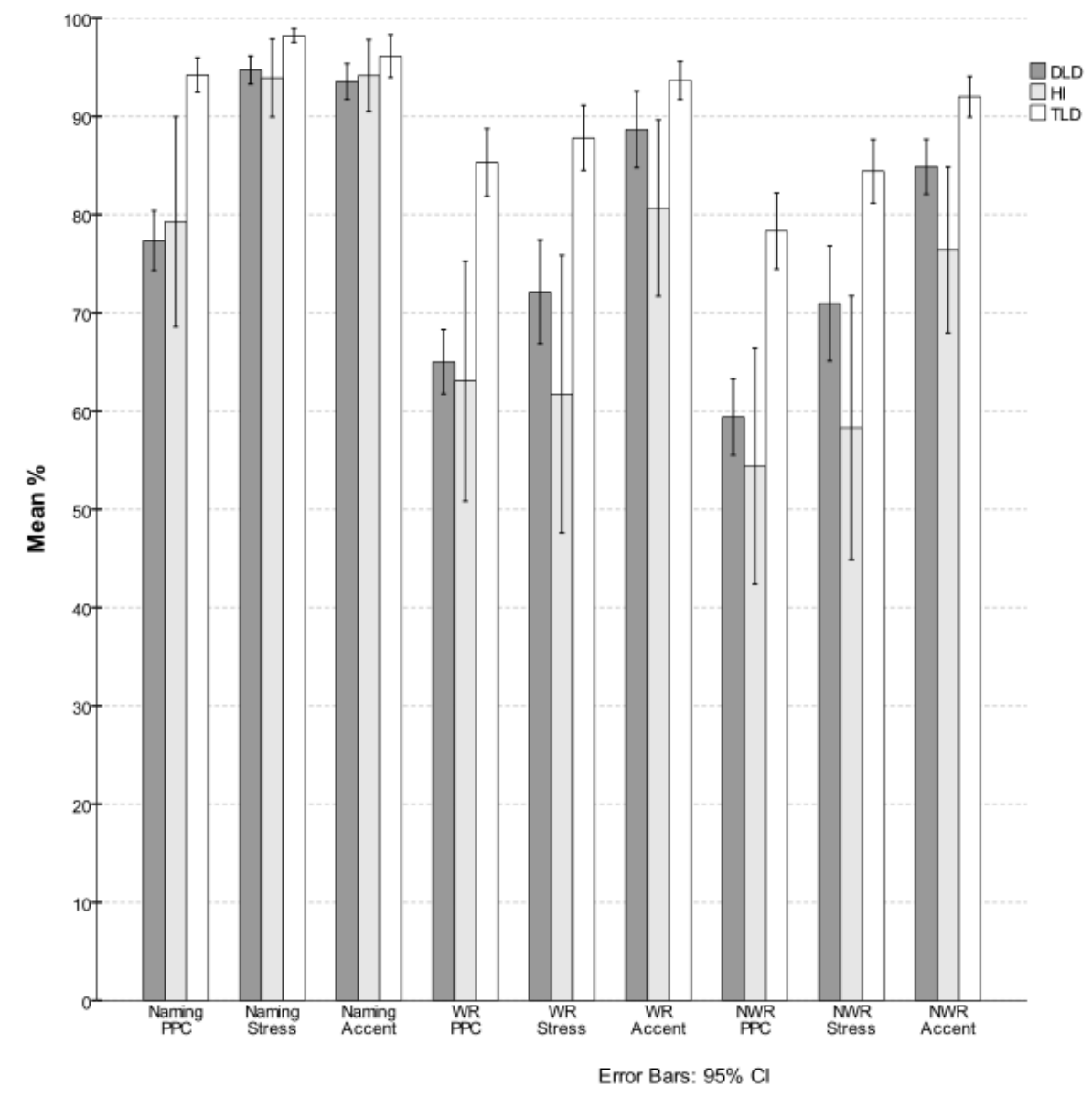

Figure 1. Results on the phonological production tasks.

a Naming

Results and Kruskal-Wallis group comparisons the Phoneme test are shown in table 2. There was a significant effect of group on the production of consonants. Pairwise comparisons revealed that the TLD group outperformed both the children with DLD $(p<0.001, r=0.72)$, and the children with HI ( $p=0.002, r=0.40)$. No difference was found between the DLD and HI groups. A significant effect of group was also found for vowel production. The relative performance was the same as for consonants, with the TLD group achieving higher scores than both children with DLD $(p<0.001, r=0.60)$ and HI $(p=0.001, r=0.41)$, while no difference was found between the latter two groups. 
The groups differed significantly on the production of stress patterns. Pairwise comparisons indicated that the higher results for the TLD group compared to the children with DLD ( $p<$ $0.001, r=0.48)$, and HI $(p<0.001, r=0.34)$. No difference was found between the groups with DLD and HI. The ability to produce tonal word accents also differed between the groups. Children with TLD scored higher than the children with DLD $(p=0.006, r=0.36)$, but no other significant differences were found.

Table 2. Descriptive statistics and group comparisons for the Phoneme test

\begin{tabular}{llllllllllll}
\hline \multicolumn{10}{c}{ DLD } & \multicolumn{1}{c}{ HI } & \multicolumn{7}{c}{ TLD } \\
\hline & $M$ & $S D$ & $95 \% C I$ & $M$ & $S D$ & $95 \% C I$ & $M$ & $S D$ & $95 \% C I$ & $H(2)$ & $p$ \\
PCC & 70.4 & 11.6 & $66.1,74.8$ & 74.2 & 23.5 & $60.6,87.7$ & 93.0 & 6.6 & $90.4,95.5$ & 38.84 & $<0.001$ \\
PVC & 89.1 & 4.8 & $87.3,90.9$ & 88.0 & 11.0 & $81.6,94.3$ & 96.3 & 2.7 & $95.3,97.4$ & 28.82 & $<0.001$ \\
Stress & 94.7 & 3.8 & $93.3,96.2$ & 93.9 & 6.9 & $90.0,97.9$ & 98.2 & 1.9 & $97.5,98.9$ & 18.69 & $<0.001$ \\
Accent & 93.5 & 4.9 & $91.7,95.4$ & 94.2 & 6.3 & $90.5,97.8$ & 96.1 & 5.7 & $94.0,98.3$ & 9.64 & 0.008 \\
\hline
\end{tabular}

Notes. All results are expressed as percentages. $\mathrm{WR}=$ word repetition; $\mathrm{NWR}=$ nonword repetition;

$\mathrm{PCC}=$ percentage of consonants correct; $\mathrm{PVC}=$ percentage of vowels correct;

Accent $=$ tonal word accent DLD $=$ developmental language disorder; $\mathrm{HI}=$ hearing impairment;

TLD = typical language development; $M=$ Mean; $S D=$ standard deviation;

95\% $C I=$ confidence interval; $H(2)=$ Kruskal-Wallis test statistic(degrees of freedom);

$p=$ probability value.

\section{$b$ Repetition of words and nonwords}

Table 3 shows group results and Kruskal-Wallis statistics for the WR and NWR task. The ability to repeat consonants, vowels, stress, and tonal word accent differed significantly between the groups in both words and nonwords, with large effect sizes throughout. Followup pairwise comparisons almost consistently revealed the same pattern: The children with DLD and the children with HI displayed lower performance than the TLD group, but they did not differ from each other. However, repetition of tonal word accents in words was lower in the HI group compared to the TLD and DLD groups, who in turn did not differ from each other. It is worth noting that the scores of the HI group were arguably lower compared to the DLD group on most of the repetition measures. Table 4 shows all pairwise comparisons for all WR and NWR measures. 
Table 3. Descriptive statistics and group comparisons for the WR and NWR measures.

\begin{tabular}{|c|c|c|c|c|c|c|c|c|c|c|c|}
\hline & DLD & & & $\mathrm{HI}$ & & & TLD & & & & \\
\hline & $M$ & $S D$ & $95 \% C I$ & $M$ & $S D$ & $95 \% C I$ & $M$ & $S D$ & $95 \% C I$ & $H(2)$ & $p$ \\
\hline WR PCC & 56.5 & 11.4 & $52.2,60.8$ & 57.8 & 22.9 & $44.7,71,1$ & 82.8 & 11.6 & $78.3,87.2$ & 33.99 & $<0.001$ \\
\hline WR PVC & 76.5 & 8.2 & $73.4,79.5$ & 70.0 & 19.2 & $59.0,81.1$ & 88.7 & 6.2 & $86.3,91.0$ & 30.35 & $<0.001$ \\
\hline WR Stress & 72.1 & 14.2 & $66.9,77.4$ & 61.7 & 24.5 & $47.6,75.9$ & 87.8 & 8.7 & $84.5,91.1$ & 27.06 & $<0.001$ \\
\hline WR Accent & 88.7 & 10.5 & $84.8,92.6$ & 80.7 & 15.5 & $71.7,89,6$ & 93.6 & 5.1 & $91.7,95.6$ & 15.59 & $<0.001$ \\
\hline NWR PCC & 47.9 & 12.4 & $43.3,52.6$ & 46.8 & 21.6 & $34.3,59.2$ & 73.0 & 13.6 & $67.8,78.2$ & 30.79 & $<0.001$ \\
\hline NWR PVC & 74.3 & 9.8 & $70.6,77.9$ & 64.4 & 19.9 & $52.9,75.9$ & 85.2 & 6.2 & $82.8,87.5$ & 23.89 & $<0.001$ \\
\hline NWR Stress & 70.8 & 15.7 & $65.1,76.8$ & 58.3 & 23.3 & $44.9,71.7$ & 84.4 & 8.5 & $81.2,87.7$ & 20.68 & $<0.001$ \\
\hline NWR Accent & 84.9 & 7.5 & $82.1,87.7$ & 76.4 & 14.6 & $68.0,84.8$ & 92.0 & 5.5 & $89.9,94.1$ & 22.69 & $<0.001$ \\
\hline
\end{tabular}

Notes. All results are expressed as percentages. WR = word repetition; NWR = nonword repetition;

$\mathrm{PCC}=$ percentage of consonants correct $\mathrm{PVC}=$ percentage of vowels correct;

Accent $=$ tonal word accent; DLD = developmental language disorder; $\mathrm{HI}=$ hearing impairment;

TLD = typical language development; $M=$ Mean; $S D=$ standard deviation;

95\% $C I=$ confidence interval; $H(2)=$ Kruskal-Wallis test statistic(degrees of freedom);

$p=$ probability value; $\mathrm{ns}=$ nonsignificant.

Table 4. Pairwise comparisons for the WR and NWR measures.

\begin{tabular}{lllllll}
\hline & TLD vs. DLD & & TLD vs. HI & & DLD vs. HI \\
\hline & $p$ & $r$ & $p$ & $r$ & $p$ & $r$ \\
WR PCC & $<0.001$ & 0.66 & 0.001 & 0.43 & $\mathrm{~ns}$ & 0.05 \\
WR PVC & $<0.001$ & 0.58 & $<0.001$ & 0.50 & $\mathrm{~ns}$ & 0.03 \\
WR Stress & $<0.001$ & 0.50 & $<0.001$ & 0.52 & $\mathrm{~ns}$ & 0.11 \\
WR Accent & $\mathrm{ns}$ & 0.22 & $<0.001$ & 0.46 & 0.046 & 0.28 \\
NWR PCC & $<0.001$ & 0.60 & $<0.001$ & 0.47 & $\mathrm{~ns}$ & 0.02 \\
NWR PVC & $<0.001$ & 0.46 & $<0.001$ & 0.50 & $\mathrm{~ns}$ & 0.13 \\
NWR Stress & 0.002 & 0.40 & $<0.001$ & 0.50 & $\mathrm{~ns}$ & 0.18 \\
NWR Accent & 0.001 & 0.42 & $<0.001$ & 0.50 & $\mathrm{~ns}$ & 0.17 \\
\hline
\end{tabular}

Notes. WR = word repetition; NWR = nonword repetition; $\mathrm{PCC}=$ percentage of consonants correct; $\mathrm{PVC}=$ percentage of vowels correct; Accent $=$ tonal word accent TLD = typical language development $;$ DLD = developmental language disorder; $\mathrm{HI}=$ hearing impairment; $p=$ probability value; $r=$ effect size;

ns $=$ nonsignificant.

\section{Grammatical production}

The effect of group on total grammatical production score was significant $(H(2)=25.38, p<$

0.001. Detailed results on the grammar test are presented below, with a section each for

verbal, nominal, and syntactic subtasks. Table 5 displays group scores for each of the

subtasks, together with Kruskal-Wallis comparisons. The subsequent follow-up pairwise

comparisons, for subtasks where a main effect of group was found, are displayed in table 6. 
Table 5. Descriptive statistics and group comparisons for the grammatical production test.

\begin{tabular}{|c|c|c|c|c|c|c|c|c|c|c|c|c|}
\hline & & DLD & & & $\mathrm{HI}$ & & & TLD & & & & \\
\hline Verbal & Max & $M$ & $S D$ & $95 \% C I$ & $M$ & $S D$ & $95 \% C I$ & $M$ & $S D$ & $95 \% C I$ & $H(2)$ & $p$ \\
\hline Present tense & 3 & 2.4 & 0.8 & $2.1,2.7$ & 2.1 & 0.7 & $1.8,2.5$ & 2.7 & 0.5 & $2.5,2.8$ & 5.94 & ns \\
\hline Past tense preterite & 3 & 1.1 & 1.2 & $0.7,1.6$ & 1.1 & 1.2 & $0.4,1.9$ & 2.3 & 0.8 & $2.0,2.6$ & 16.32 & $<0.001$ \\
\hline Future tense & 3 & 1.5 & 0.9 & $1.2,1.8$ & 1.3 & 1.1 & $0.7,1.9$ & 1.9 & 0.9 & $1.5,2.2$ & 3.55 & ns \\
\hline Past tense perfect & 3 & 1.3 & 1.0 & $0.9,1.7$ & 1.1 & 1.0 & $0.5,1.6$ & 2.1 & 1.0 & $1.7,2.5$ & 12.18 & 0.002 \\
\hline Copula & 3 & 2.4 & 0.8 & $2.1,2.7$ & 2.0 & 1.0 & $1.4,2.6$ & 2.8 & 0.4 & $2.7,3.0$ & 11.39 & 0.003 \\
\hline \multicolumn{13}{|l|}{ Nominal } \\
\hline Plural & 3 & 2.4 & 0.9 & $2.1,2,7$ & 2.3 & 0.9 & $1.8,2.8$ & 2.6 & 0.5 & $2.4,2.8$ & 0.71 & ns \\
\hline Indefinite article & 3 & 1.5 & 0.9 & $1.1,1.8$ & 1.0 & 0.8 & $0.5,1.5$ & 2.1 & 1.0 & $1.7,2.5$ & 13.59 & 0.001 \\
\hline Definite form & 3 & 2.0 & 1.0 & $1.6,2.4$ & 1.2 & 1.1 & $0.6,1.9$ & 2.7 & 0.6 & $2.5,2.9$ & 19.10 & $<0.001$ \\
\hline Noun phrase agreement & 4 & 1.1 & 1.3 & $0.7,1.6$ & 0.5 & 0.8 & $0.1,0.9$ & 1.6 & 1.1 & $1.2,2.0$ & 9.31 & 0.010 \\
\hline Predicative agreement & 3 & 2.4 & 0.9 & $2.1,2.7$ & 1.6 & 0.9 & $1.0,2.1$ & 3.0 & 0.2 & $2.9,3.0$ & 29.30 & $<0.001$ \\
\hline Genitive case & 3 & 2.1 & 1.0 & $1.8,2.5$ & 1.6 & 1.2 & $0.9,2.3$ & 2.6 & 0.6 & $2.3,2.8$ & 7.50 & 0.024 \\
\hline \multicolumn{13}{|l|}{ Syntax } \\
\hline Negation placement & 3 & 1.9 & 1.0 & $1.5,2.2$ & 2.3 & 0.9 & $1.8,2.8$ & 2.3 & 1.0 & $2.0,2.7$ & 4.30 & ns \\
\hline Relative clause & 3 & 2.6 & 0.8 & $2.3,2.9$ & 2.5 & 0.9 & $2.0,3.0$ & 3.0 & 0.2 & $2.9,3.0$ & 6.22 & 0.045 \\
\hline Topicalization & 4 & 3.1 & 1.3 & $2.6,3.5$ & 2.7 & 1.4 & $1.9,3.5$ & 2.6 & 1.5 & $2.0,3.2$ & 1.23 & ns \\
\hline
\end{tabular}

Notes. DLD = developmental language disorder; $\mathrm{HI}=$ hearing impairment; TLD = typical language development;

Max = maximum score; $M=$ Mean $S D=$ standard deviation; $95 \% C I=$ confidence interval;

$H(2)=$ Kruskal-Wallis test statistic(degrees of freedom); $p=$ probability value; $\mathrm{ns}=$ nonsignificant.

Table 6. Pairwise comparisons for subtasks of the grammatical production test.

\begin{tabular}{lllllll}
\hline & \multicolumn{2}{l}{ TLD vs. DLD } & \multicolumn{2}{c}{ TLD vs. HI } & \multicolumn{2}{c}{ DLD vs. HI } \\
\hline Verbal & $p$ & $r$ & $p$ & $r$ & $p$ & $r$ \\
Past tense preterite & $<0.001$ & 0.43 & 0.009 & 0.35 & $\mathrm{~ns}$ & 0.00 \\
Past tense perfect & 0.011 & 0.34 & 0.010 & 0.35 & $\mathrm{~ns}$ & 0.07 \\
Copula & $\mathrm{ns}$ & 0.25 & 0.004 & 0.38 & $\mathrm{~ns}$ & 0.18 \\
Nominal & & & & & & \\
Indefinite article & 0.032 & 0.30 & 0.002 & 0.41 & $\mathrm{~ns}$ & 0.17 \\
Definite form & 0.022 & 0.31 & $<0.001$ & 0.50 & $\mathrm{~ns}$ & 0.25 \\
Noun phrase agreement & $\mathrm{ns}$ & 0.21 & 0.008 & 0.35 & $\mathrm{~ns}$ & 0.19 \\
Predicative agreement & 0.025 & 0.31 & $<0.001$ & 0.63 & 0.003 & 0.39 \\
Genitive case & $\mathrm{ns}$ & 0.18 & 0.021 & 0.32 & $\mathrm{~ns}$ & 0.17 \\
Syntax & & & & & & \\
Relative clause & $\mathrm{ns}$ & 0.24 & $\mathrm{~ns}$ & 0.25 & $\mathrm{~ns}$ & 0.06 \\
\hline
\end{tabular}

Notes. TLD = typical language development; DLD = developmental language disorder;

$\mathrm{HI}=$ hearing impairment; $p=$ probability value; $r=$ effect size; $\mathrm{ns}=$ nonsignificant.

Only subtasks with significant main effects of group according to the Kruskal-Wallis tests are included.

\section{a Verbal morphology}

No significant differences between the groups were found for present tense inflection (stem-

er) or construction of the future tense (ska 'will' + infinitive verb). For the ability to produce

past tense preterite (stem-te), past tense perfect (har 'has' + stem-t), and copula (är 'is'), there

was a significant effect of group (see table 5). Pairwise comparisons (table 6) yielded the 
same relations between the groups for all of these variables; the TLD control group performed higher than the DLD and HI groups, who in turn did not differ significantly from each other.

\section{b Nominal morphology}

Plural inflection (noun-ar/-er/-or) did not differ significantly between the groups, while there was a significant effect of group on production of indefinite articles (en/ett 'a/an'), definite form (stem-en/-n/-t 'the'), noun phrase agreement (article + adjective + noun), predicative agreement (subject + copula + adjective), and genitive case (noun-s) (see table 5). For indefinite articles and definite forms, pairwise comparisons (table 6) revealed that the children with TLD achieved higher scores than the children with DLD and HI, but there was no difference between the two latter groups. Agreement in noun phrases and use of genitive was more challenging for the children with HI compared to children with TLD, but not compared to children with DLD. No difference was found between the children with DLD and TLD. Correct predicative agreement was higher for the children with TLD compared to the groups with DLD and HI. The children with DLD also performed above the children with HI on this task.

c Syntax

The groups did not differ from one another in the syntax subtasks negation placement (auxiliary verb + inte 'not' + verb) or topicalization word order (topicalized word + verb + subject). For relative clauses (som 'who/that' + verb), there was a significant difference as indicated by the Kruskal-Wallis test. However, the subsequent pairwise comparisons failed to detect any significant differences. 


\section{Discussion}

The children with DLD or HI achieved equal results on all aspects of the naming task, but were generally below the controls with TLD, who performed near ceiling on all measures. Performance in all three groups was quite high for both production of vowels, stress patterns, and tonal word accents. For tonal word accent production, there were no significant differences between the groups. Tonal word accent is realized over the whole word, but needs to be aligned with the stressed syllable. The correct tonal word accent can, however, be realized correctly even if a word is stressed on the wrong syllable. The largest differences between the clinical groups and the controls was found for consonant production, both in naming and repetition of words and nonwords. Consonants in general have less acoustic energy and shorter duration than vowels, features that might pose problems for children with DLD or HI (Leonard et al., 1997; Svirsky et al., 2002).

The pattern of results was consistent for both the WR and NWR tasks: phonological production did not differ significantly between the children with DLD or HI, but the performance of both groups was lower than that of the children with TLD. This relation between the groups was the same regardless of whether the stimuli to be repeated were familiar (words) or unfamiliar (nonwords). The only exception was that the children with DLD repeated tonal word accents in words with the same accuracy as the controls, unlike children with HI who did not do this to the same degree. Like in the picture naming task, tonal word accent scores were relatively high. Consonants, on the other hand, proved to be very difficult to repeat for both the DLD group and the HI group (less than $60 \%$ correct in words and less than $50 \%$ in nonwords for both clinical groups). There was a trend for vowel, stress, 
and tonal word accent repetition to be lower in the HI group than in the DLD group, but no significant differences were found due to the small sample sizes and large variability, especially among the children with HI.

Although lower performance, compared to the control group, children with DLD and children with HI were equal on the production of indefinite articles (e.g. ett äpple 'an apple'; en katt 'a cat') and definite form suffixes (äpple-t 'the apple'; katt-en 'the cat'). These tasks require the correct use of articles (en/ett 'a/an') and endings (-en or $-n /-e t)$ with respect to gender. Indefinite articles comprise unstressed syllables that occur in pretonic positions, i.e. before the stress of the upcoming noun, outside of the predominant strong-weak pattern of Swedish, making them hard to perceive and produce (Gerken, 1994). The definite form suffixes also constitute unstressed syllables, but in the target forms of Gramba they are in a position immediately after the stressed syllable, inside of a strong-weak prosodic structure. Thus, definite form could be regarded as easier than articles, and they also develop earlier. However, it could not be concluded from the results of the present study that there was a difference between these grammatical elements for either children with DLD or HI.

Noun phrase agreement was the overall most challenging grammar task for all three groups. The children with HI and DLD achieved similar results on this task, but performed below the children with TLD. The task requires the child to produce phrases ranging from three to five syllables, where all elements are in agreement. Also, agreement is expressed partly through articles and suffixes that occur in perceptually disadvantaged positions, e.g. in det gula äpplet 'the yellow apple' /det gula eplet/, [de'gùzla 'èplet], and in ett gul-t hus 'a yellow house' /et gult hus/, [عt'gú:lt 'hú:s]. Here, the articles det/ett comprise unstressed pretonic syllables, 
outside of the strong-weak structure. Further, the definite form suffix $-t$ in $\ddot{a p p l e-t}$ is in the coda position of an unstressed syllable, and the neuter agreement inflection $-\mathrm{t}$ of $g u l-t$ is, although in a stressed syllable, the last consonant of a complex coda—both of which are challenging positions (Demuth, 2014). The low performance in general, and for the children with HI in particular (with a mean of only 0.5 out of 4), may partly have been due to the combined demands on phonological working memory and processing of segments and syllables in prosodically weak positions. The predicative agreement task is similar in this respect, with target structures between four and six syllables in length, and obligatory unstressed copula before a stressed syllable, as well as agreement expressed by suffixes comprising unstressed syllables or coda consonants (e.g. hus-et är stor-t 'the house is big'

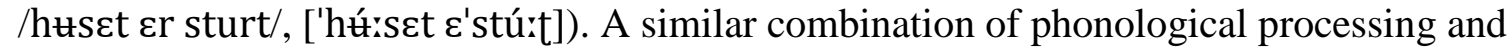
phonological working memory load should be reflected in NWR performance (Gathercole, 2006; Bowey, 2006), but without the grammatical component. The present results on NWR showed a clear disadvantage for children with DLD or HI in comparison with the controls, but not for children with HI compared to those with DLD. This is in line with the results on the noun phrase agreement task, but not the predicative agreement task, which proved to be more difficult for the children with HI compared to children with DLD. So, while NWR did not capture a difference between the two clinical groups, the arguably more complex predicative agreement task did. The reasons for why children with HI should have more problems with this task cannot be explained based on the present findings, but warrants further investigation of the interface between working memory, phonology and grammar.

Grammatical production in the syntax subtasks emerged as a relative strength for the children with DLD or HI in the present study. This finding is somewhat surprising considering that syntactic impairments are common in both populations (Lederberg et al., 2013; Leonard, 
2014). The tasks measuring production of negation placement, relative clauses, and topicalization word order require utterances with the right syntactical elements in the right order. With the exception of negations (inte 'not'), relative pronouns (som 'who/that') and topicalized words (e.g. sen 'then'), the child is free to choose any appropriate words as long as they belong to the correct syntactic category. Further, the requirements on phonetic and phonological accuracy is lower than in the morphology tasks, which likely also contributed to the more age-appropriate results on these tasks (Nittrouer et al., 2014; Nittrouer et al., 2016). It is possible that standardised tests that include only a limited variety of syntactic structures, such as the Gramba, do not capture important aspects of syntactic ability. Subsequently, tasks with higher syntactic complexity, or production in spontaneous speech or narratives, may reveal a different picture of syntactic production in children with DLD or HI. Still, the present results showed markedly higher results on the syntax subtasks compared to the verbal and nominal morphology tasks.

A limitation of the present study is that several factors that may influence both phonology and grammar were unaccounted for. For instance, between-groups differences in phonological and grammatical production would possibly have been more valid, had the groups been matched for e.g. lexicon size or quality. Future studies should also control more carefully for socioeconomic status. The lower maternal education length in the HI group compared to the TLD group may have put the children with $\mathrm{HI}$ at a disadvantage. Differences in language ability between these two groups could therefore in part reflect e.g. unequal language stimulation in their home environments. 
The findings of the present study need replication with larger sample sizes, especially given that the group of children with HI was small, with considerable heterogeneity. Also, more detailed analyses may provide insights into qualitative differences between the children with DLD and the children with HI. For example, the phonological production measures were exclusively quantitative, and do not capture e.g. what phonological features were problematic in each group.

\section{Implications}

Large variability in the group of children with HI should be taken into account in the assessment of phonological working memory, phonological processing and production, and grammatical production. Some children performed on par with typically developing children with $\mathrm{NH}$, while the majority achieved results below or well below age-adequate levels. The relative strength in syntactic ability in both children with DLD and children with HI may also have clinical implications, since this means that using e.g. syntactic bootstrapping in the treatment of e.g. phonological, lexical and grammatical impairments may be beneficial for these children. The demonstrated problems with both verbal and nominal morphology should also be taken into consideration in intervention planning.

\section{Conclusions}

The children with DLD and children with HI in the present study performed below controls on phonological production during naming and repetition of words and nonwords, as well as on verb and noun morphology. Production of tonal word accents emerged as a relative strength, as did syntax. Regarding both phonology and grammar, children with DLD and HI reached similar levels of performance, with the exception of noun-adjective agreement in 
predicative, where children with DLD achieved higher scores. Future experimental studies of tasks that could discriminate between these groups are encouraged, as they might highlight language problems that are uniquely characteristic for each clinical population (DLD and HI).

\section{Declaration of conflicting interest}

The authors declare no potential conflicts of interest with respect to the research, authorship, or publication of this article.

\section{Funding}

The authors received no financial support for the research, authorship, or publication of this article.

\section{References}

Berglund E and Eriksson M. (2000) Communicative development in Swedish children 16-28 months old: The Swedish early communicative development inventory - Words and sentences. Scandinavian Journal of Psychology 41: 133-144.

Bishop DVM, Snowling MJ, Thompson PA, et al. (2017) Phase 2 of CATALISE: a multinational and multidisciplinary Delphi consensus study of problems with language development: Terminology. Journal of Child Psychology and Psychiatry 58: 1068-1080.

Bowey JA. (2006) Clarifying the phonological processing account of nonword repetition. Applied Psycholinguistics 27: 548-552.

Bruce G. (1977) Swedish word accents in sentence perspective, Lund: Liber.

Bruce G. (2012) Allmän och svensk prosodi, Lund, Sweden: Studentlitteratur.

Clark JG. (1981) Uses and abuses of hearing loss classification. ASHA 23: 493-500. 
Cleary M. (2009) Language disorders in children with hearing impairment. In: Schwartz R (ed) Handbook of child language disorders. Hove: Psychology Press, 90-115.

Coady JA and Evans JL. (2008) Uses and interpretations of non-word repetition tasks in children with and without specific language impairments (SLI). International Journal of Language and Communication Disorders 43: 1-40.

Cohen J. (1992) A power primer. Psychological bulletin 112: 155-159.

Delage H and Tuller L. (2007) Language development and mild-to-moderate hearing loss: Does language normalize with age? Journal of Speech, Language, and Hearing Research 50: 13001313.

Demuth K. (2014) Prosodic licensing and the development of phonological and morphological representations. In: Farris-Trimble A and Barlow J (eds) Perspectives on phonological theory and development: In honor of Daniel A. Dinnsen. John Benjamins Publishing Company, 1124.

Dollaghan CA and Campbell TF. (1998) Nonword repetition and child language impairment. Journal of Speech, Language, and Hearing Research 41: 1136-1146.

Gathercole SE. (2006) Nonword Repetition and Word Learning: The Nature of the Relationship. Applied Psycholinguistics 27: 513-543.

Gerken L. (1994) A metrical template account of children's weak syllable omissions from multisyllabic words. Journal of Child Language 21: 565-584.

Halliday LF, Tuomainen O and Rosen S. (2017) Language development and impairment in children with mild to moderate sensorineural hearing loss. Journal of Speech, Language, and Hearing Research 60: 1551-1567.

Hansson K and Nettelbladt U. (2004) Gramba. Grammatiktest för barn [Grammatical assessment for children]. Malmö, Sweden: Pedagogisk Design.

Hansson K, Nettelbladt U and Leonard LB. (2003) Indefinite articles and definite forms in Swedish children with specific language impairment. First Language 23: 343-362.

Hellqvist B. (1995) Fonemtest [Phoneme test], Löddeköpinge: Pedagogisk design. 
Håkansson G and Hansson K. (2007) Grammatisk utveckling. In: Nettelbladt U and Salameh E-K (eds) Språkutveckling och språkstörning hos barn. Lund: Studentlitteratur, 135-169.

Ibertsson T, Willstedt-Svensson U, Radeborg K, et al. (2008) A methodological contribution to the assessment of nonword repetition - A comparison between children with specific language impairment and hearing-impaired children with hearing aids or cochlear implants. Logopedics Phoniatrics Vocology 33: 168-178.

Lederberg AR, Schick B and Spencer PE. (2013) Language and Literacy Development of Deaf and Hard-of-Hearing Children: Successes and Challenges. Developmental psychology 49: 15-30.

Leonard LB. (2014) Specific language impairment across languages. Child Development Perspectives 8: $1-5$.

Leonard LB, Eyer JA, Bedore LM, et al. (1997) Three accounts of the grammatical morpheme difficulties of English-speaking children with specific language impairment. Journal of Speech, Language, and Hearing Research 40: 741-753.

Nettelbladt U. (2007) Fonologisk utveckling. In: Nettelbladt U and Salameh E-K (eds) Språkutveckling och språkstörning hos barn. Lund, Sweden: Studentlitteratur, 57-81.

Nittrouer S, Caldwell-Tarr A, Sansom E, et al. (2014) Nonword Repetition in Children With Cochlear Implants: A Potential Clinical Marker of Poor Language Acquisition. American Journal of Speech-Language Pathology 23: 679.

Nittrouer S, Lowenstein JH and Holloman C. (2016) Early predictors of phonological and morphosyntactic skills in second graders with cochlear implants. Research in developmental disabilities 55: 143-160.

Peters AM and Strömqvist S. (1996) The role of prosody in the acquisition of grammatical morphemes. In: Demuth JLMK (ed) Signal to syntax: Bootstrapping from speech to grammar in early acquisition. Hillsdale, US: Lawrence Erlbaum Associates, Inc, 215-232.

Riad T. (2014) The phonology of Swedish, Oxford: Oxford University Press.

Sahlén B, Reuterskiöld-Wagner C, Nettelbladt U, et al. (1999) Non-word repetition in children with language impairment - Pitfalls and possibilities. International Journal of Language and Communication Disorders 34: 337-352. 
Schwartz R. (2009) Specific language impairment. In: Schwartz R (ed) Handbook of child language disorders. Hove: Psychology Press, 3-43.

Sundström S, Löfkvist U, Lyxell BR, et al. (2018) Prosodic and segmental aspects of nonword repetition in 4- to 6-year-old children who are deaf and hard of hearing compared to controls with normal hearing. Clinical Linguistics and Phonetics: 1-22.

Sundström S, Samuelsson C and Lyxell B. (2014) Repetition of words and non-words in typically developing children: The role of prosody. First Language 34: 428-449.

Svirsky MA, Stallings LM, Lento CL, et al. (2002) Grammatical morphologic development in pediatric cochlear implant users may be affected by the perceptual prominence of the relevant markers. Annals of Otology, Rhinology and Laryngology 111: 109-112.

Tomblin JB, Records NL, Buckwalter P, et al. (1997) Prevalence of specific language impairment in kindergarten children. Journal of Speech, Language \& Hearing Research 40: 1245.

Wechsler D. (2005) Wechsler Preschool and Primary Scale of Intelligence. Swedish version., Stockholm, Sweden: Psykologiförlaget AB. 